\title{
Cultural Image Translation Strategies from the Perspective of Eco-Translatology
}

\author{
Yanjie Xu \\ School of Foreign Languages, Shanxi Datong University, Datong, China \\ Email: shenyuedouzi@126.com
}

How to cite this paper: Xu, Y. J. (2021). Cultural Image Translation Strategies from the Perspective of Eco-Translatology. Creative Education, 12, 1207-1214.

https://doi.org/10.4236/ce.2021.126090

Received: April 13, 2021

Accepted: May 30, 2021

Published: June 2, 2021

Copyright $\odot 2021$ by author(s) and Scientific Research Publishing Inc. This work is licensed under the Creative Commons Attribution International License (CC BY 4.0).

http://creativecommons.org/licenses/by/4.0/

\begin{abstract}
The connection between language and culture determines that translation is not only the superficial transformation of language symbols, but also the deep transformation and transplantation of different cultures. Domestication and free translation of unique cultural images in the source language often fail to convey the unique cultural connotation of the source language, which will lead to the loss of the source language culture in the target language and greatly reduce the cultural value of translation. This paper studies cultural images in literary translation from the perspective of eco-translatology, and points out that cultural images not only have high literary aesthetic value, but also have rich cultural connotations, which play an important role in promoting literary communication and cultural dissemination. On this basis, this paper probes into the translation methods of translating cultural images, which are mainly foreignization and supplemented by domestication, and discusses the phenomenon of cultural loss when cultural images are transmitted in the process of literary translation.
\end{abstract}

\section{Keywords}

Cultural Image, Literary Translation, Cultural Function

\section{Introduction}

Cultural image is not an isolated language symbol. It has intertextuality in essence. According to the theory of intertextuality, the composition of any text is the absorption and transformation of other texts (Li \& Zhu, 2016). This means that cultural image is also composed of the language symbols of cultural image and the dependent connection between its cultural signified, which is the result of the combination of language symbols and cultural meaning (Wei et al., 2019). After a long period of exploration and research in translation at all times and in all over the world, equivalence theory seems to have developed to a near perfect 
level (Chen, 2016). Many translators regard it as the guiding principle of translation. However, when dealing with the translation of cultural images, the consideration of the recipient's response is often contradictory to the goal of cultural transmission. On the basis of information theory, we should go beyond the rigidly bound comparison and entanglement of the two languages, emphasize the dynamic equivalence of information, and focus on the response of the target readers (Wang, 2011). Comparing the response of the target readers with that of the original readers, it includes not only the understanding of the information function of the two languages, but also the understanding and appreciation of the expression function, empathy function, aesthetic function and other functions (Zhang, 2017). Under the background of cultural globalization, the "cultural turn" of translation has become inevitable.

Because human beings form the same and similar association with some things in social practice, there is a certain degree of overlap between different cultures, and thus different degrees of equivalence relationship are formed in the process of translation $(\mathrm{He}, 2016)$. Image is a method often used in literary creation. The use of image, in essence, is to express abstract things with concrete things, enlighten unknown or difficult to know with known or easy to know (Wang, 2015). The intertextual nature of cultural image reveals the participation value of cultural image in a specific cultural discourse space, and reflects the relationship between cultural image and its language symbols, knowledge codes, cultural representation and other factors (Liao, 2011). The focus of contemporary translation theory research has shifted from comparative analysis of language structure and translation semantic equivalence to linguistic and cultural comparison and cultural translation strategies (Chai, 2001). Image refers to the specific image with a special meaning and literary significance in literary works. It is an amorphous and creative meaning, finding a fixed and expressive image, and a combination of abstract meaning and concrete image ( $\mathrm{Gu}, 2011)$. This paper studies the cultural images in literary translation from the perspective of eco translatology, and points out that cultural images not only have high literary aesthetic value, but also have rich connotative cultural information, which play an important role in promoting literary exchange and cultural communication.

\section{The Role and Dilemma of the Principle of Equivalent Effect in the Translation of Cultural Images}

Since 1950s, many translation theorists at home and abroad have made detailed discussions on translation equivalence. For example, Cartford's "textual equivalence”, Qian Zhongshu's “transformation”, Fu Lei's "emphasizing resemblance but not resemblance", Xu Yuanchong's "seeking resemblance but not resemblance" and other translation theories all talk about equivalence in translation. Eugene Nida put forward the "equivalence theory" as a complete theory. Nida himself advocates that free translation is the first step in translation, and puts forward the famous dynamic equivalence theory: "The natural equivalence that is closest to the source language information is reproduced in the receiving lan- 
guage, first meaning equivalence, then stylistic equivalence" (Zhang, 2002).

Translation is a tool of cultural communication, which is responsible for helping human beings to exchange thoughts and feelings, spread cultural knowledge and promote social civilization. Translation is not only a code-switching at the linguistic level, but also a cross-cultural transformation of spreading cultural information. Different languages have great differences in pronunciation, grammar and vocabulary, which bring insurmountable difficulties to translators. For example, Chinese belongs to Sino-Tibetan language structure, while English belongs to Indo-European language structure. It is difficult to realize the equivalent conversion between them at the language level. The purpose of communication is to enable two or all parties involved in communication to communicate and understand each other. In order for participants to communicate and understand each other, it is necessary to convey information clearly and accurately. Because different languages have different information bearing and expression forms, it is necessary to change the expression forms of the source language for translation. The equivalence principle is not limited to the surface structure of language, but seeks a higher level of dynamic equivalence, thus providing a new perspective and space for translators' work. Its philosophical foundation is the common core of human thinking, and people of all nationalities have similar life experiences and common language (Chen \& Han, 2004). Due to the differences in natural geographical environment, humanistic environment and life thinking habits, different language groups and nationalities in different regions of the world have produced rich and different historical cultures. Each language not only reflects the concept of the objective world and the common experience of mankind, but also carries its own unique history and culture, cognitive thinking mode and belief. To some extent, the transformation of language symbols is only the surface of translation, while the essence of translation lies in the dissemination of cultural information. Therefore, in order to convey the cultural images in the source language profoundly and properly to the target readers, translators must understand the characteristics and differences between English and Chinese cultures. Table 1 shows the statistical data of the introduced book types.

Because the languages and thinking of different nationalities are strikingly similar in some aspects, cultural images, as a unique generalization and expression of a certain language, sometimes have the same similar connotations and associations in another cultural tradition. There is no difficulty in guiding this kind of translation with the principle of equal effect. If translation only conveys semantics approximately and loses cultural connotation, semantic communication is incomplete, unfaithful and fails to achieve translation goals. Domesticating the cultural concepts in the source language text into the target language culture in translation is an effort to give up the original and go to the end. The purpose of translation is to promote cultural communication, not to realize cultural unification. Introducing rich culture from the source language into the target language will greatly enrich and develop the target language, and make its cultural connotation and language expression art more colorful. In the process 
Table 1. Statistics on categories of books introduced by copyright.

\begin{tabular}{cccccccc}
\hline $\begin{array}{c}\text { Particular } \\
\text { year }\end{array}$ & Technology & Novel & Biography & $\begin{array}{c}\text { Reference } \\
\text { book }\end{array}$ & $\begin{array}{c}\text { Coaching } \\
\text { books }\end{array}$ & Religion & Other \\
\hline 2020 & 3387 & 1749 & 352 & 261 & 842 & 87 & 6754 \\
\hline
\end{tabular}

of translation, the intertextuality of cultural images is firstly an internal intertextuality, which is open to the source culture. As far as the target culture is concerned, it is closed. In essence, the realization of intertextuality of cultural images in translation has reflected the relationship of mutual influence, reference and reference among different cultures, and at the same time, it has changed the closed nature of intertextuality of cultural images to the open nature of target culture (Song \& Hu, 2016).

There can be several translations of the same source text, which can be considered as dynamic equivalence or functional equivalence. The key is whether the translated text can produce the corresponding effect of the original text in the cultural background of the target language. Different nationalities often have their unique cultural images because of their different living environments and cultural traditions. This has caused great difficulties for literary translators. Figure 1 is a typical model of translation studies.

As the main body of translation activities, the translator and the author have a dialogue across time and space in the process of translation, and carry out activities based on the choice and re-creation of the source text, often suffering from the "tribulation" of the multiple meanings of the source text. This pluralistic intentional activity interacts in the infinite network of cultural images, and translation can be completed in the mutual reference of many texts. Macroscopically speaking, the commonness of human thinking, life experience and language makes it possible to translate equally between any two languages. In fact, excellent works of English-Chinese and Chinese-English translation abound, and the translations of some famous works have become an important part of the treasure house of philology. At this time, it is effective to use the principle of equal effect to guide translation. Nida's idea is enlightening to translation practice, at least it can make us carefully consider the image transmission when transmitting the source language information. Nida's theory is constantly improving. Although it has been criticized since it was put forward, the cornerstone of functional equivalence has not wavered. Nida's equivalence theory has broad guiding significance, and will not lose its theoretical value because of the passage of time and the emergence of new translation theories.

\section{Cultural Image and Its Translation}

Foreignization and domestication are two interrelated translation strategies, which can be regarded as an extension of the traditional concepts of literal translation and free translation, but these two concepts are not completely equivalent. Literal translation and free translation mainly focus on how to deal 


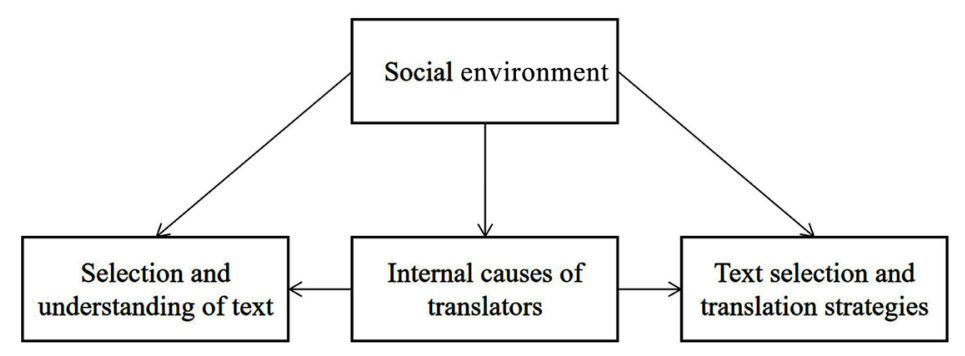

Figure 1. Overview model of translator research.

with form and meaning at the linguistic level, while foreignization and domestication expand their horizons to the linguistic, cultural and aesthetic levels, thus breaking through the limitations of linguistic factors. Language is the carrier, product and important component of culture, so we can say that language and culture are closely related. Different nationalities breed different cultures, and there are different differences between different cultures. The core idea of foreignization and domestication is the value orientation based on the cultural context, rather than sticking to the value orientation at the language level. Generally speaking, foreignization requires the translator to approach the author and reproduce the content of the original text in a way that the readers of the source language are accustomed to. When the images in the source language can produce consistent or similar effects in the target language, that is, the readers' reactions are the same, literal translation can be adopted to retain the cultural images. For example, both English and Chinese have a large number of phrases with animals as images, which are vivid and intuitive, and easy to produce direct image effects, and then associate with the cultural connotations they carry.

Based on the important position of cultural images in literary translation, translators should carefully study the aesthetic value of cultural images and the connotative cultural information they carry, carefully analyze readers' cultural horizons and receptivity, comprehensively consider various factors and carefully choose translation strategies. Translation of cultural images should not only consider language differences, but also pay close attention to cultural differences. How to deal with cultural differences is often the key to the success or failure of translation. There are many words with rich cultural characteristics in both English and Chinese. In translating such words, we should adhere to a general principle: on the one hand, we should convey the cultural characteristics of the source language as much as possible; on the other hand, we should not exceed the target language culture and the acceptability of the target language readers. When the cultural connotations of the images in the source language cannot be accurately expressed in the target language, they can be replaced by images that conform to the expression habits of the target language and are familiar to the target readers. In this way, although the image of the source language is discarded, the corresponding image in the target language can still be used to make the target readers have similar or similar reactions to the source language readers and obtain roughly the same artistic feelings. With the development of translation and cross-cultural communication, many foreign cultural images 
have been accepted by Chinese readers. When translating such cultural images, it is unnecessary to explain, process or replace them with Chinese cultural images. The composition of communicative competence is shown in Figure 2.

Alienation translation is faithful to the original text and the original author, which is conducive to maintaining the artistic image of the original text, enriching the language and culture of the target language, embodying cultural equality and promoting cultural exchange. However, excessive alienation will make the language of the translated text unsmooth, thus affecting readers' understanding of the translated text. Generally speaking, the expressions with foreign cultural characteristics are often figurative languages, and preserving the figurative languages in the original text is equivalent to reserving opportunities for Chinese readers to understand western culture. At the same time, the continuous introduction of fresh images is also conducive to improving the interpretation and digestion ability of Chinese culture to foreign cultures. Behind the contradiction between literal translation and free translation lies the contradiction between domestication and foreignization in essence ( $\mathrm{Lu} \& \mathrm{Rao}, 2015)$. Traditional translation theory generally emphasizes content over form, and often uses the cultural images of one's own nation to copy the cultural images of other nations, so that the target readers can get the same strong feelings as the original readers. Any language has "alienation tolerance", and readers will have a kind of expectation for different cultures when reading works translated from foreign languages. The translation model based on big data can be expressed in pyramid form according to the depth of language break-up, as shown in Figure 3.

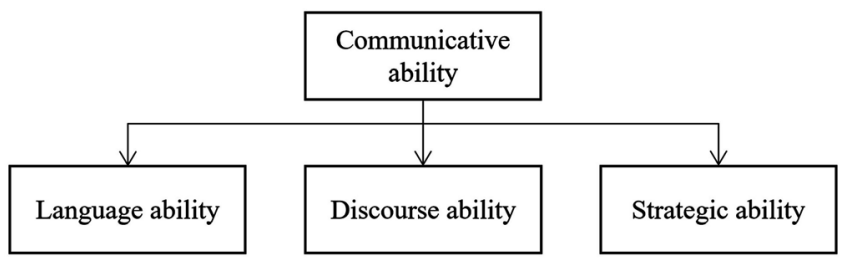

Figure 2. The composition of communicative competence.

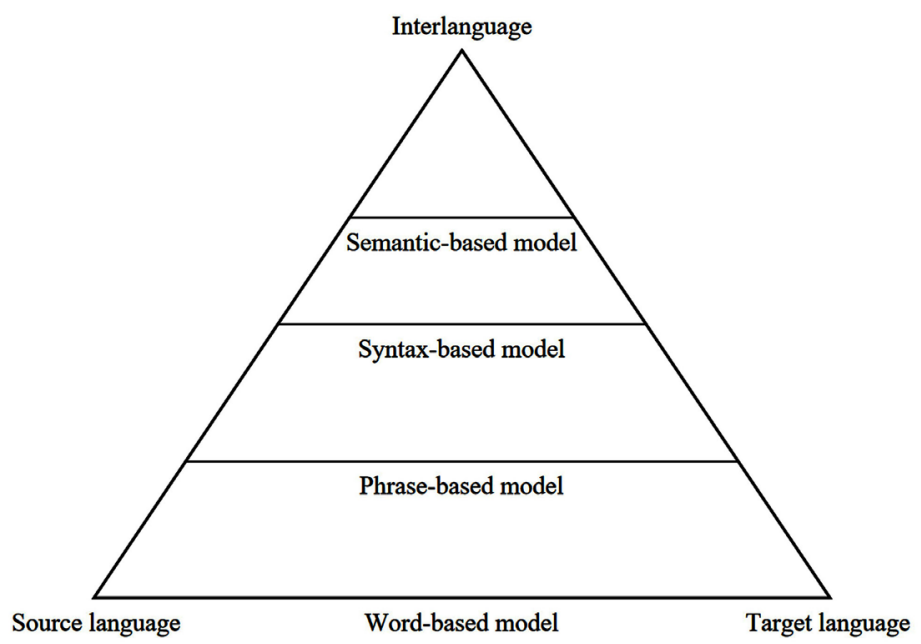

Figure 3. Translation model pyramid based on statistics. 
The key to the intertextuality of cultural images is to use the semantics of images to arouse readers' imagination, so that they can feel the exotic atmosphere of cultural images in the source language. In the translation of cultural images, the translator has to abandon the literal meaning of the original text when he is limited by the social and cultural differences of the target language, in order to achieve a free translation method which is consistent with the content of the original text and has similar main language functions. Because cultural images are often the crystallization of a nation's wisdom rather than the works of a writer or author, this contradiction is more reflected in the translation of cultural images as the target language or the target language. Although this difference does not affect the translator's understanding of the basic semantics of intertextual texts, it is difficult to reproduce the original meaning of cultural images, that is, to completely reproduce the intertextuality of cultural images in the same form, because the parent structure on which cultural images depend has changed, and the cultural images reconstructed by translators are only a possible approximate reproduction.

\section{Conclusion}

Culture is diversified, and the diversity of culture makes all ethnic groups have many vivid cultural images. However, due to the differences in natural environment, social system, religious belief, customs, ways of thinking, etc., there are also great differences in the expression of languages bearing culture. Alienated literal translation of cultural translation should avoid the simple understanding of literal translation as "qualitative translation", and avoid the problem that translation is not up to standard, because the target language is too "qualitative". Whether the image is properly handled directly affects the success of translation. Grasping cultural images can deepen the translator's understanding of intertextuality and improve his translation strategies. This intertextual relationship is manipulated by the translator, whether it is delivered directly or rewritten in a meaningful way, which can't get rid of the translator's grasp of the social and cultural intertextuality outside the text. On the basis of being familiar with the source culture and the target culture, translators must translate with a high sense of responsibility and coordinate the relationship between the principle of equal effect and the transmission of cultural factors, so as to seek the best combination of the two. Interpreting cultural images in translation from the perspective of intertextuality will inevitably bring new inspiration to translation studies, which can not only help scholars better understand translation activities, but also improve translators' ability to deal with text and extra-text factors in translation.

\section{Acknowledgements}

This work was supported by a study on the differences between Eastern and Western Thinking Modes Embodied in Chinese Modern Prose Translation (No. 2015Q28). 


\section{Conflicts of Interest}

The author declares no conflicts of interest regarding the publication of this paper.

\section{References}

Chai, M. P. (2001). Reconstruction, Modification and Transformation of Cultural Images in Film Translation. Journal of Suzhou University (Philosophy and Social Sciences Edition), No. 4, 91-94.

Chen, J. L. (2016). Three-Dimensional Transformation of Tourism Translation from the Perspective of Ecological Translation. Journal of Chongqing Jiaotong University (Social Science Edition), 86, 122-129.

Chen, T., \& Han, L. (2004). Treatment of Cultural Image in Poetry Translation. Journal of Shandong University of Technology (Social Science Edition), 20, 101-104.

$\mathrm{Gu}$, J. M. (2011). The Intertextuality and Translation of Cultural Images from the Perspective of Relevance Theory. Foreign Language Teaching, No. 5, 110-113.

He, H. L. (2016). The Construction of Translation Teaching Model from the Perspective of Ecological Translation. Journal of Hubei Correspondence University, 172, 149-150.

Li, M. J., \& Zhu, W. (2016). The Translation of Public Signs for Tourist Attractions in Ethnic Regions from the Perspective of Ecological Translation. Guizhou Ethnic Studies, 179, 124-127.

Liao, B. P. (2011). The Dialectics of Domestication and Foreignization in Cultural Image Translation. Crazy English (Teacher Edition), No. 1, 166-170.

Lu, R. X., \& Rao, H. H. (2015). An Empirical Study of Translation Teaching Model from the Perspective of Eco-Translation Studies. Overseas English, 316, 143-145.

Song, Z. P., \& Hu, G. S. (2016). Eco-Translational Interpretation of Some Key Issues in Translation Studies. Foreign Language Teaching, 177, 111-114.

Wang, F. (2015). The Application of Functional Teleology in the Translation of Film and Television Cultural Images. Journal of Kaifeng Institute of Education, 35, 54-55.

Wang, W. Q. (2011). The Translation of Cultural Images from the Perspective of Cognitive Language Methodology. Journal of Baoji University of Arts and Sciences (Social Science Edition), No. 3, 92-95.

Wei, B., Hu, X. H., \& Zang, G. Y. (2019). A Probe into the Translation Strategies of Yuxian Paper-Cut Cultural Images in Skopos Theory. Communication Research, 80, 54-55.

Zhang, J. (2017). Research on the Translation of Cultural Image of Film and TV Drama Lines. The House of Drama, No. 2, 108-109.

Zhang, Z. Q. (2002). Context and the Translation of Cultural Image Words. Journal of Xi'an International Studies University, 10, 22-25. 